https://doi.org/10.46344/JBINO.2021.v010i01.22

\title{
IMPACT ASSESSMENT OF THE ACTIVITIES OF SOIL LIPASE AND DEHYDROGENASES IN SPENT ENGINE OIL-POLLUTED ECOSYSTEM UNDERGOING REMEDIATION
}

EBULUE, M.M.

Pollution Control and Biotechnology Unit, Department of Biochemistry, Paul University Awka. Anambra State, Nigeria.

Email: ebuluemm801f@yahoo.com

\begin{abstract}
Activities of soil microbial exudates (lipase and dehydrogenases) reflect the extent of metabolism in an ecosystem polluted with spent engine oil undergoing remediation. This study investigated these ex-situ using biochemical tools during the bio-augmentation with poultry droppings. The result revealed that at $1.0-3.5 \%$ contamination across days-zero to -28 , spent engine oil which significantly $(p<0.05)$ inhibited the activity of soil lipase from $5.80 \pm 0.10$ to $1.80 \pm 0.05 \mathrm{~mol} / \mathrm{min}$ was significantly $(p<0.05)$ stimulated from $5.80 \pm 0.10$ to $6.50 \pm 0.01 \mathrm{~mol} / \mathrm{min}$ during the bio-augmentation. Conversely, the activity of soil dehydrogenases which was significantly $(p<0.05)$ stimulated from $4.72 \pm 0.01$ to $9.78 \pm$ $0.04 \mathrm{~mol} / \mathrm{min}$ suffered inhibition significantly $(p<0.05$ ) from $4.72 \pm 0.01$ to $3.80 \pm 0.10 \mathrm{~mol} / \mathrm{min}$ during soil enrichment with poultry droppings. These two groups of enzymes have demonstrated that they could be used in concert as biomarkers of hydrocarbon-polluted soil ecosystem undergoing remediation. The inhibition in the activity of soil dehydrogenases occasioned during bio-augmentation will forestall the catabolic removal of the pollutant by this enzyme. The activity of these enzymes which was concentration and time dependent of the pollutant and bio-augmenting agent affected the entire soil biochemistry. Ecosystem dynamics and mineralization which were impaired and disrupted during the contamination were restored during the remediation process.
\end{abstract}

Keywords: Soil, spent engine oil, lipase, dehydrogenases, poultry droppings. 


\section{INTRODUCTION}

Contamination of the existing and potential agricultural lands is the fundamental problem associated with the processing, distribution, usage and disposal of crude, refined and spent engine oil. These spillages have attracted great public interests and concerns with rescue response activities thereafter. Following onshore or near shore spillages, the soil and other components of the terrestrial ecosystem being the primary recipients are inevitably affected. In an aquatic environment, the oil sometimes floats on water surface, where it is disposed to shorelines by wind and wave actions, invariably affecting the soil. But in a completely terrestrial environment, the penetration and spread of the oil is a function of the nature of the topography of the soil (Osuji and Ezebuiro 2006). The soil is a prime factor in agricultural productivity and socio-economic activities; therefore, any threat or substantial impairment usually affects the people's livelihood and galvanizes into public outcry.

Spent engine oil, which is also known as used mineral-based crankcase oil, is a brown-to-black liquid produced when new mineral-based crankcase oil is subjected to high temperature and high mechanical strain (ATSDR, 1997). It is a mixture of several different chemicals such as low and high molecular weight $\left(C_{15}-C_{20}\right)$ aliphatic and aromatic hydrocarbons and heavy metals. It is a common and toxic environmental contaminant; though biodegradable is not found in natural environment (Dominguez-Rosado and Pichtel, 2004). It is introduced into the environment from the exhaust system during engine use, engine leakage or when the engine oil is changed and disposed into gutters, water drains, farmlands; a common practice of motor and generator mechanics (Anoliefo and Edegbai, 2000; Osubor and Anoliefo, 2003).

Impact assessment which is a systematic and repetitive collection and analysis of data that can be used to determine the quality of the environments as they are or would be was conducted to evaluate the biological response to spent engine oil and the response was extrapolated from its effect on microbial exudates, the enzymes. Spent engine oil impact on soil ecosystem induces insurgence of hydrocarbon degrading microorganisms, but on the other hand induces a limitation in microbial diversity (Ebulve ef al., 2017). This effect which altered the entire soil biochemistry could disrupt ecosystem dynamics by slowing soil organic matter mineralization and associated nutrient re-mineralization (Ebulue et al., 2017).

The activities of soil microbial exudates (lipase and dehydrogenases) reflect the extent of metabolism in an ecosystem polluted with spent engine oil and or undergoing remediation. Soil enzymatic activities which have a central role in the 
soil environment are used as attractive bio-indicators for monitoring various impacts on soil (Ebulve et al., 2017; Bayer et al., 1982). The activities of soil lipase and dehydrogenases are the most common indices used to describe microbial activities during hydrocarbon contamination and decontamination.

Dehydrogenases (EC 1.1.1.1) are enzymes that catalyze the removal of hydrogen atoms from substrates (Nelson and Cox, 2008). Active dehydrogenases are considered to exist in the soil as the integral part of intact cells with a broad range of oxidative activities that are responsible for degradation of soil organic matter (Margesin et al., 2000; Öhlinger, 1996). Lipase catalyzes the hydrolysis of p-nitrophenol butyrate, with the release of $\mathrm{p}$-nitrophenol when incubated in an oil-polluted soil. The inhibition and induction in the activity of the enzyme is a valuable marker of an ecosystem undergoing contamination and remediation of hydrocarbon.

Remediating the oil impacted soil with nutrients to bio-augment and biostimulate microbial activity accelerates recovery because oil impacted soil remains impacted for long periods unless remedied; and large oil spills limit microbial ability to degrade hydrocarbons.

\section{Research design}

This research was designed for a-fortytwo-day investigation in consideration of the volatility and biodegradability of hydrocarbons:

Day- zero

Day- 14

Day- 28 and
Day- 42;

within which, the activities of the aforementioned enzymes were evaluated as a function of time and concentration of the pollutant.

\section{Methodology (materials and methods) Materials}

Project site: Soil microcosms for this study was collected from three sites within the Paul University premises in Awka, Anambra State Nigeria with a soil auger inserted about $15 \mathrm{~cm}$.

Test sample: Spent engine oil was obtained randomly from three different mechanic villages in Awka, Anambra State of Nigeria and pooled together to obtain a composite sample meant for the analysis. Poultry droppings were collected from a poultry farm at Awka, Anambra State Nigeria.

\section{Methods}

Soil preparation: From the soil samples collected within the University premises, $20 \mathrm{~kg}$ was weighed, dried at ambient temperature $\left(25-27^{\circ} \mathrm{C}\right)$, crushed in a porcelain mortar and sieved with cheesecloth to remove tiny stones and other particulate matters. The fractions (10g), after contamination with spent engine oil at different concentrations (1.0, $1.5,2.0,2.5,3.0$, and $3.5 \% \mathrm{w} / \mathrm{w}$ ) were used for the determination of the activity of soil microbial exudates; the enzymes (dehydrogenases and lipases).

For the remediation; into the different levels of contaminations of the soil samples, were amended with $5 \mathrm{ml}$ corresponding to $50 \% \mathrm{v} / \mathrm{w}$ each of the poultry droppings after five days of post contamination according to Moffat (1995) method of applying organic manure to the soil to increase microbial activity. 


\section{Determination of the activity of dehydrogenases}

Principle: The activity of dehydrogenases was determined using the method described by Tabatabai, (1982). Dehydrogenases convert 2,3,5-triphenyl tetrazolium chloride (TTC) to formazan. The asbsorbance of formazan was read spectrophotometrically at $485 \mathrm{~nm}$.

Protocol: $10 \mathrm{~g}$ of sieved soil was placed into test tubes containing different concentrations of spent engine oil: 1.0, 1.5, 2.0, 2.5, 3.0, 3.5\% w/w (oil-soil mixture), and into the blank, distilled water. Then, $5 \mathrm{ml}$ of $3 \%(\mathrm{w} / \mathrm{v})$ aqueous 2,3,5-triphenyl tetrazolium chloride was added into all the tubes, mixed and stirred with a glass rod. After $96 \mathrm{~h}$ of incubation at $27^{\circ} \mathrm{C}, 10 \mathrm{ml}$ of ethanol was added to each test tube and the suspension was vortexed for 30 s. The tubes were then incubated for $1 \mathrm{~h}$ to allow suspended soil to settle. The resulting supernatant was carefully transferred into clean test tubes, and the absorbance was read spectrophotometrically at $485 \mathrm{~nm}$. The concentration of formazan was evaluated using the molar extinction coefficient of dehydrogenases at $15433 \mathrm{Mol} \mathrm{cm} \mathrm{cm}^{-1}$ Dushoff, (1965); and the activity was determined thereafter as follows: $A=E C L$ where $C=A / E L$. Activity = $\mathrm{mol} / \mathrm{min}$.

\section{Determination of the activity of soil lipase}

Principle: A colorimetric determination of soil lipase activity using the method of Schinner et al. (1996) where the substrate, p-nitrophenyl butyrate was incubated with the soil samples at $27{ }^{\circ} \mathrm{C}$ and the absorbance of the released $\mathrm{p}$ nitrophenol was determined colorimetrically at $400 \mathrm{~nm}$ with the molar extinction coefficient of $1.48 \times 10^{-2} \mathrm{M}^{-1} \mathrm{~cm}^{-}$ 1 .

Protocol: A colorimetric method for determination of soil lipase activity of Schinner et al. (1996) was used, where the substrate, p-nitrophenyl butyrate was incubated with the soil samples at $27 \circ \mathrm{C}$. Soil inoculation was carried out by weighing $10 \mathrm{~g}$ of sieved soil sample into six different test tubes. To the first tube, $0.1 \mathrm{~g}$ of spent engine oil (corresponding to $1.0 \%$ ) was added and mixed thoroughly with a steering rod. This procedure was repeated for 1.5, 2.0, 2.5, 3.0 and 3.5\%; and into the $7^{\text {th }}$ tube, the control, $20 \mathrm{ml}$ of distilled water was added. After 10 minutes incubation at room temperature and centrifugation at $7000 \mathrm{~g}$, the resulting supernatant was carefully transferred into clean test tubes and the absorbance of the released p-nitrophenol was determined colorimetrically at 400nm with the molar extinction coefficient of $1.48 \times 10^{-2} \mathrm{M}^{-1} \mathrm{~cm}^{-1}$ and the activity was determined thereafter as follows: $A=E C L$ where $C=A / E L$. Activity $=\mathrm{mol} / \mathrm{min}$.

\section{Statistical analysis}

The results were expressed as mean \pm standard deviation (SD). All results were compared with respect to the control. Comparisons between the concentrations and control were made by using Statistical Package for Social Sciences (SPSS) version 20 and One-way Analysis of Variance (ANOVA). Differences at $\mathrm{p}<0.05$ were considered significant.

\section{RESULT}

Spent engine oil stimulated the activity soil dehydrogenases. The increase which was significant $(p<0.05)$ when compared 
between groups was concentration and time dependent as presented in Fig. 1.0. Spent engine oil inhibited the activity of soil lipase. Comparison between groups showed the inhibition which was statistically significant $(p<0.05) \quad$ when compared between groups was in a concentration and time dependent manner as shown in Fig. 2.0.

Remediation with poultry droppings produced converse results in the activities of the aforesaid

enzymes;

Figs. 3.0 - 8.0.

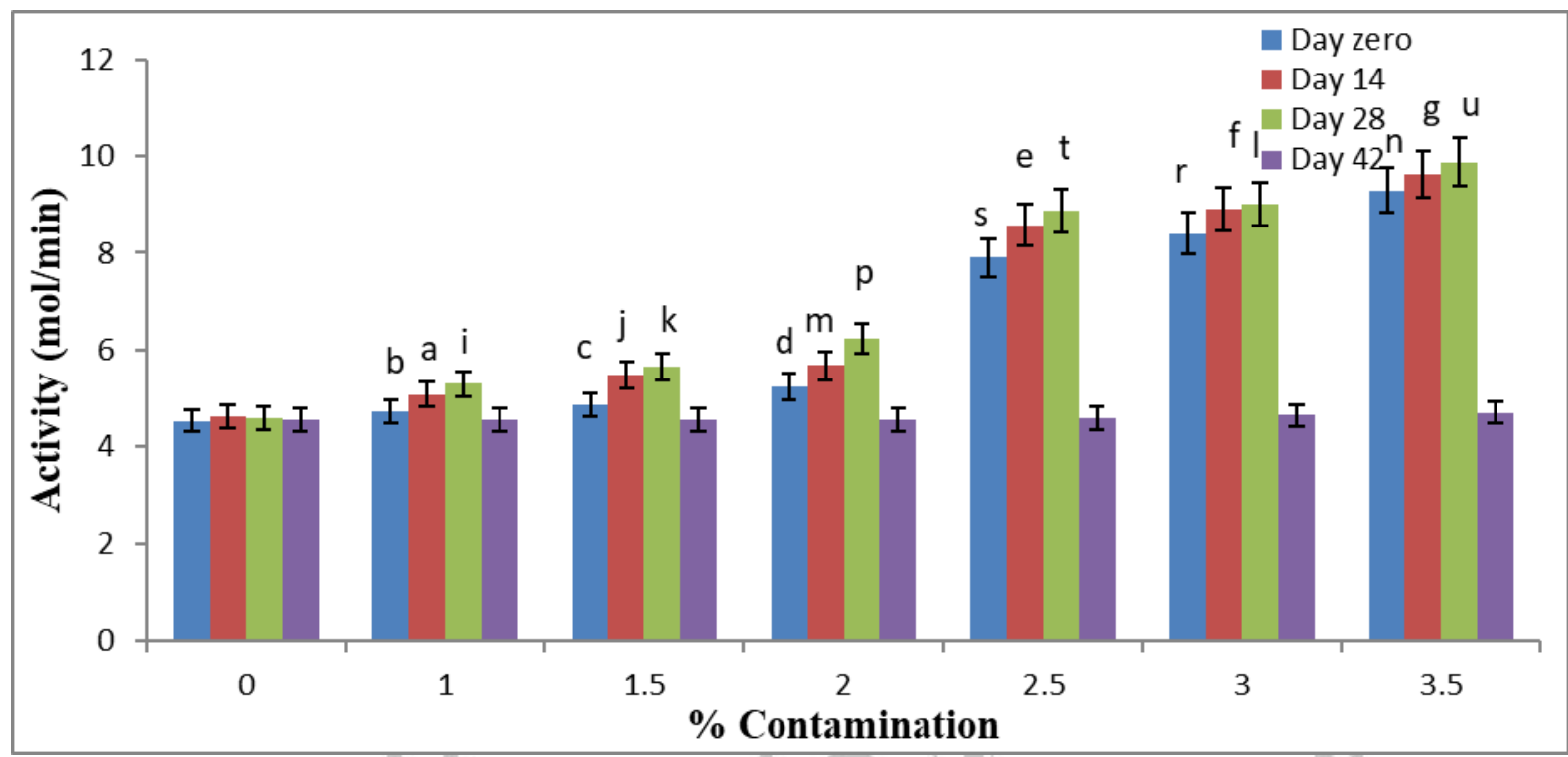

Fig.1: Activity of soil dehydrogenases in spent engine oil-pollution; Comparison between groups:

Bars with different letters differ significantly $(\mathbf{p}<0.05)$.

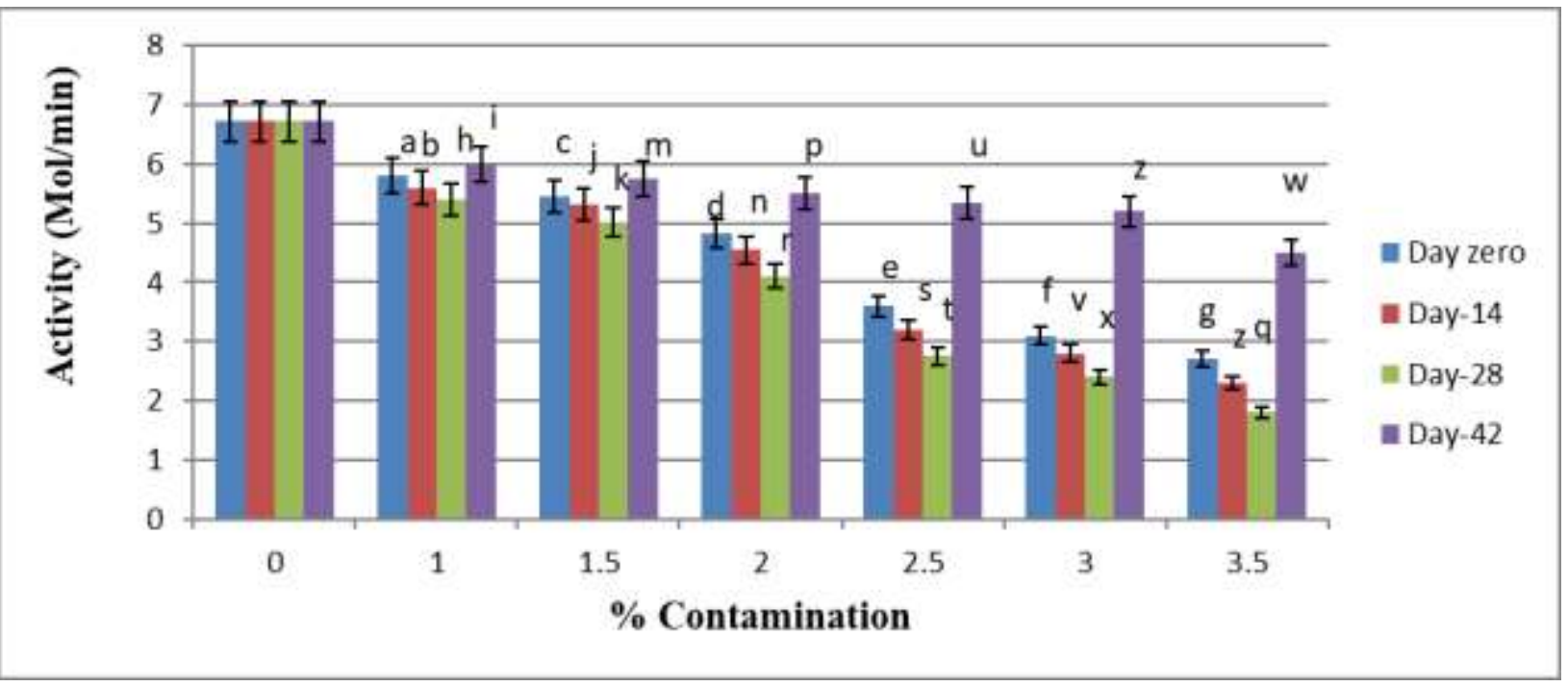


Fig.2: Soil lipase activity in the spent engine oil pollution; Comparison between groups: Bars with different letters differ significantly $(\mathbf{p}<0.05)$.

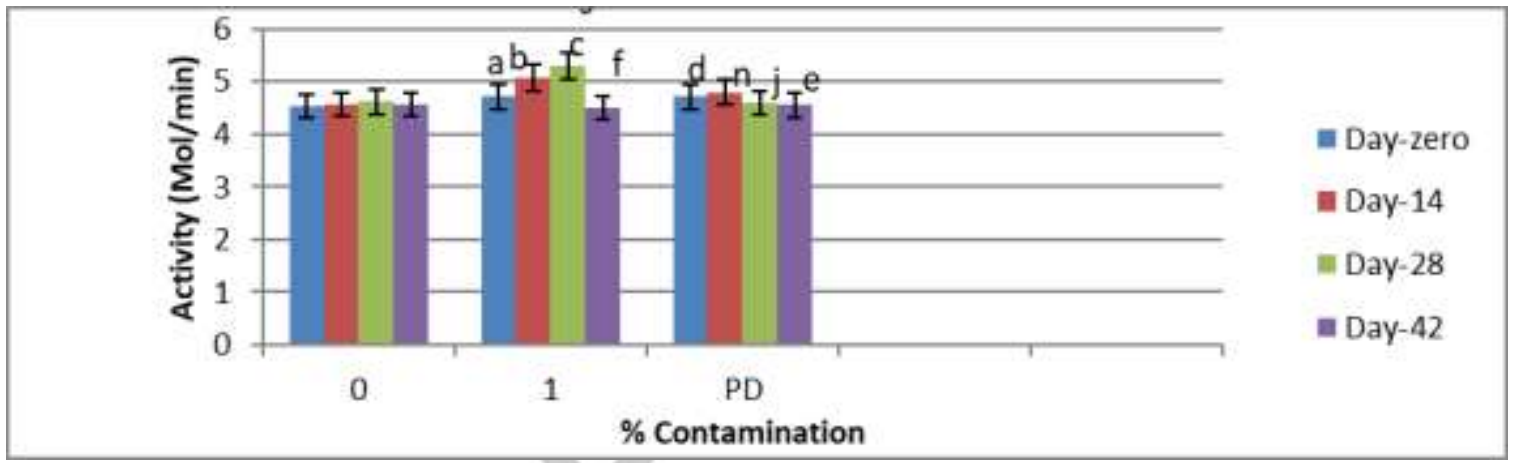

Fig.3: Soil dehydrogenase activity at $1.0 \%$ contamination and bio-augmentation with poultry droppings; Bars with different letter differ significantly $(p<0.05)$

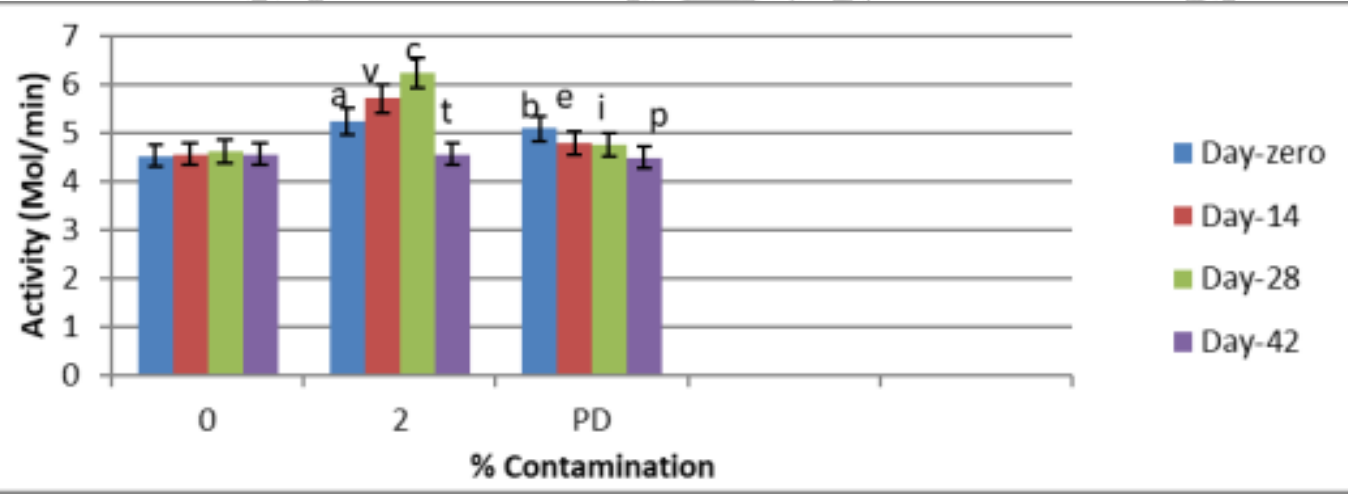

Fig.4: Soil dehydrogenase activity at $\mathbf{2 . 0 \%}$ contamination and bio-augmentation with poultry droppings; Bars with different letter differ significantly $(p<0.05)$ 


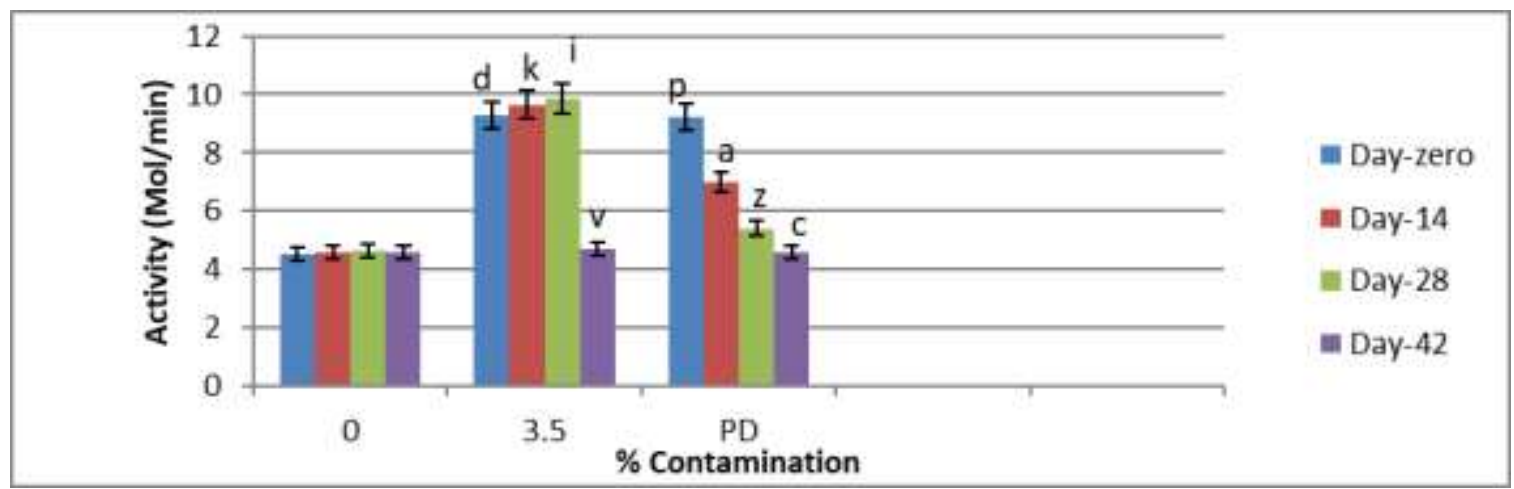

Fig.5: Soil dehydrogenase activity at $3.5 \%$ contamination and bio-augmentation with poultry droppings; Bars with different letter differ significantly $(p<0.05)$

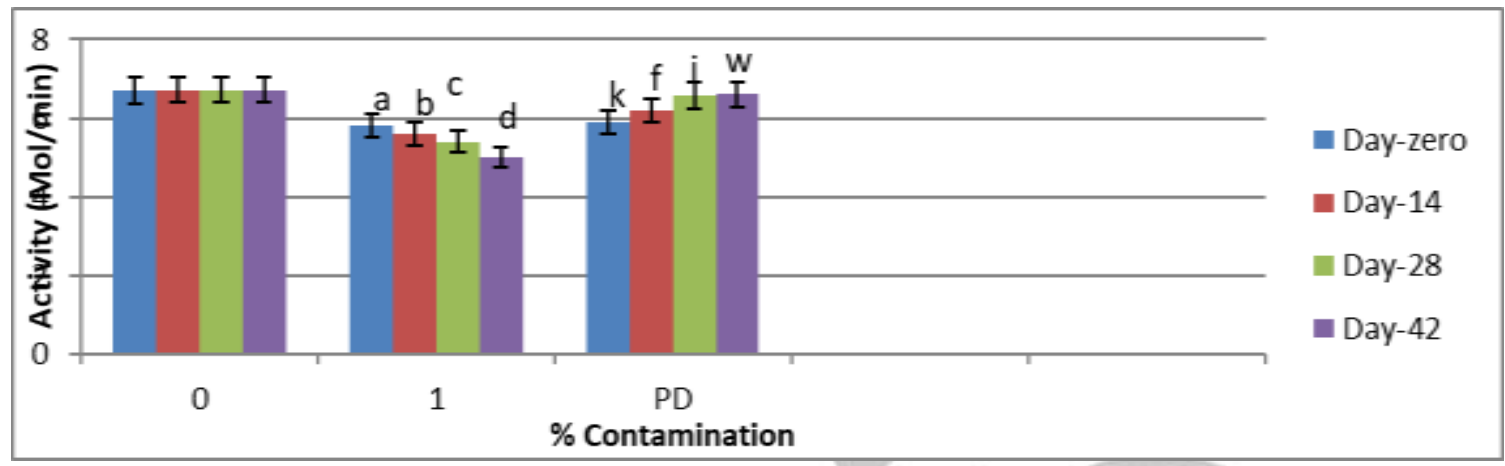

Fig.6: Soil lipase activity at $1.0 \%$ contamination and bio-augmentation with poultry droppings; Bars with different letter differ significantly $(p<0.05)$.

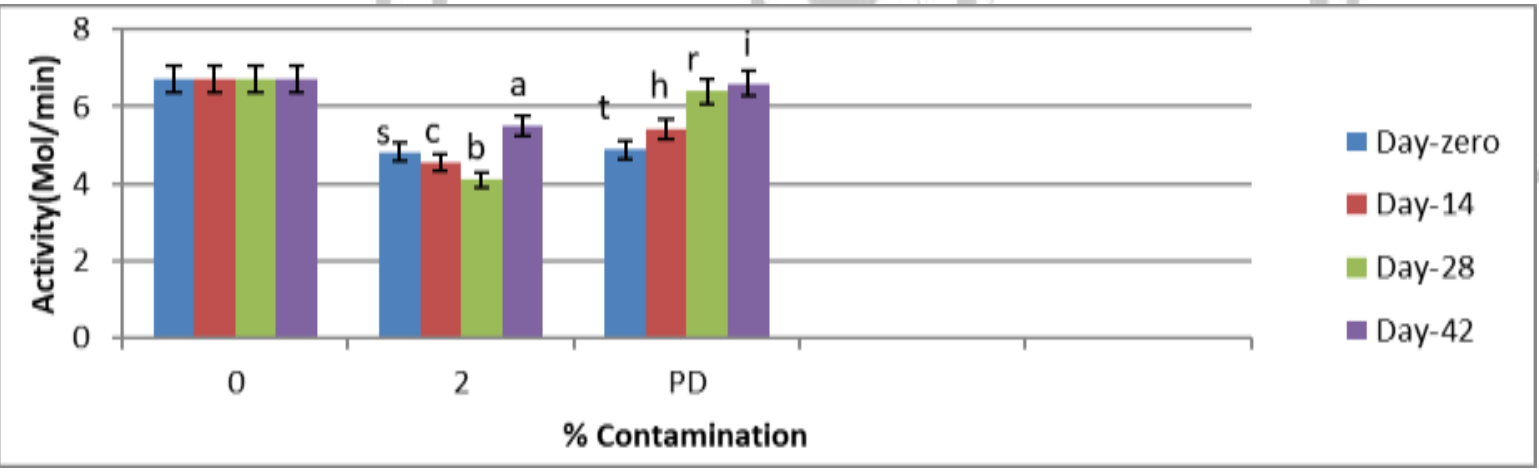

Fig.7: Soil lipase activity at $\mathbf{2 . 0 \%}$ contamination and bio-augmentation with poultry droppings; Bars with different letter differ significantly $(\mathbf{p}<0.05)$. 


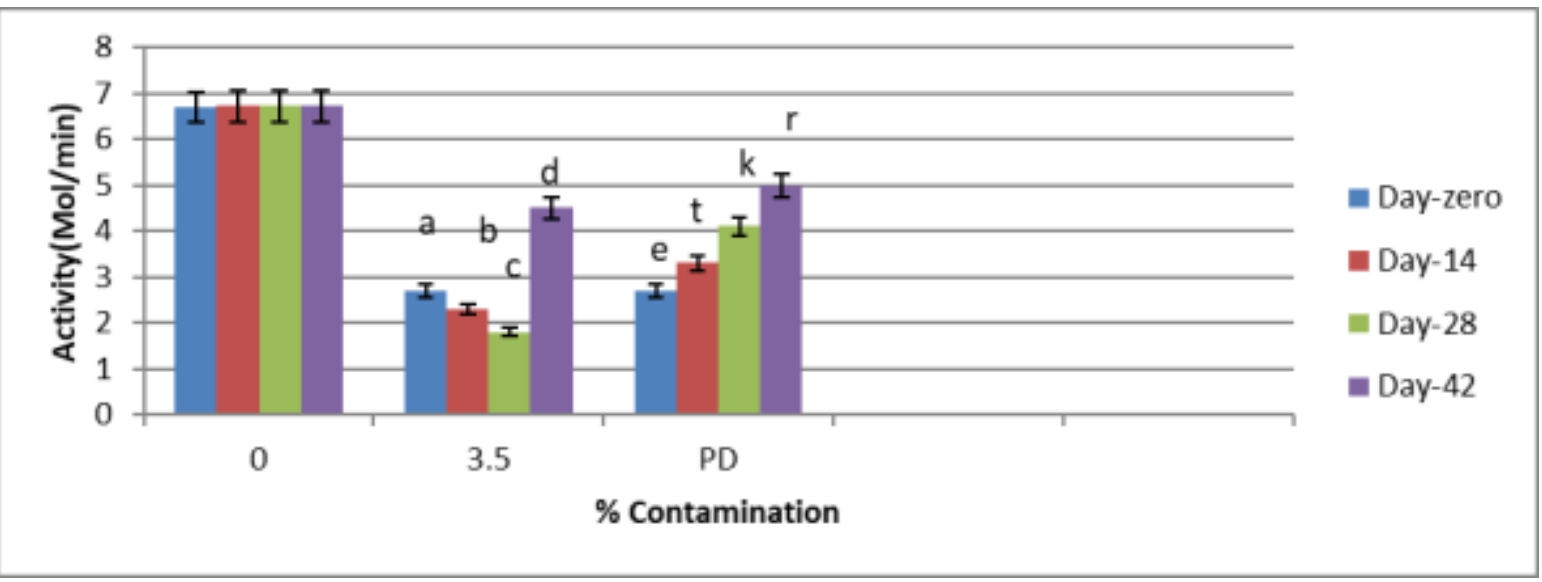

Fig.8: Soil lipase activity at 3.5\% contamination and bio-augmentation with poultry droppings; Bars with different letter differ significantly $(p<0.05)$.

\section{DICUSSION}

Assessment of the activities of soil microbial exudates, (the enzymes) from possible impact of spent engine oil on soil ecosystem is imperative for the determination of environmental acceptability. In this study, the activities of soil lipase and dehydrogenases were investigated in two phases, viz, during the impact of spent engine oil and during the recovery phase.

Spent engine oil inhibited the activity of soil lipase significantly $(p<0.05)$. The inhibition paralleled the concentration of the contaminant overtime which could arise from unfavorable conditions such as hypoxia and reducing environment occasioned in the oil-polluted ecosystem indicating that oil biodegradation by microorganisms and metabolic enzymes could lead to production of organic acids (Ebulve et al., 2017). It could also imply that the amino acids at the active site of soil lipase are irritable to hypoxic and acidic environment arising from the impact (Ebulue et al., 2017). This finding is in consonance with the report of Margesin and Schinner (1999) on the inhibition of the activity of soil lipase following an insult of soil ecosystem with spent oil.

On the other hand, this investigation revealed that spent engine oil increased the activity of soil dehydrogenases significantly ( $\mathrm{p}<0.05$ ). This stimulatory effect was stronger as the rate of contamination and duration of contact increased. However, by day-42, the enzyme activities began to decline, a condition which is correlated with the depletion of the pollutants, microbial induction, enzyme induction and activity. The induction and repression in enzyme concentration synergized in the increase and decrease in their activities overtime which is a function of the upsurge in hydrocarbonclastic organisms (Ebulue et al., 2017) correlated with the concentration of the contaminant. These two groups of enzymes have demonstrated that they could be used in concert as biomarkers of hydrocarboncontaminated soil ecosystem. This finding 
is in harmony with the work of Achuba and Peretiemo-Clarke (2008) on the activities of the enzyme in spent engine oil pollution.

The use of biological agents to control the problems of environmental pollution is remediation. The essence of remediation by nutrient application is to bio-augment and bio-stimulate microbial degradation and this is the hallmark of recovery of petroleum hydrocarbon-contaminated soils in environmental biotechnology.

Bio-augmentation enhances delivery of inorganic phosphate (Pi) and nitrogen $\left(N_{2}\right)$ in the immediate vicinity of the oil impacted soil and this overcomes the toxic inhibition imposed by hydrocarbons, decreases the acidity, increases the microbial biomass and optimizes the activity of the adapted microorganisms and then creates an environment ideal for microbial degradation.

Remediation with bio-augmenting agent, poultry droppings, inhibited significantly $(p<0.05)$ the activity of soil dehydrogenases which was stimulated during hydrocarbon contamination from spent engine oil. Conversely, the activity of soil lipase which was inhibited during spent engine oil contamination was gradually relieved of the inhibition following the bio-augmentation with the organic fertilizer, poultry droppings. This revelation was not surprising because chicken manure had been known to create a suitable $\mathrm{pH}$ environment for microbial and enzymatic activities. This result is in harmony with the observations of Bello et al. (2009) who suggested that animal waste, in particular chicken manure, may provide the necessary chemical and microbial initiators to trigger remediation of hydrocarbonpolluted soil from oil spillage.

\section{Conclusion}

Spent engine oil caused a shift in equilibrium and energy imbalance in the affected ecosystem. It altered the entire soil biochemistry. Microbial activities and their exudates are veritable indices of spent oil polluted soil. The enzymatic activities of dehydrogenases and lipase in the affected ecosystem provide information on the activities of hydrocarbonclastic organisms during contamination and decontamination with poultry droppings.

\section{REFERENCES}

Achuba, F.I. and Peretiemo-Clarke, B.O. (2008). Effect of spent engine oil on soil catalase and dehydrogenase activities. International Agrophysics, 22: 1 - 4 .

Anoliefo, G.O. and Edegbai, B.O. (2000). Effect of spent engine oil as an oil contaminant on the growth of two eggplant species; Solanum melongena L. and S. incanum. Journal of Agricultural Forestry Fisheries, 1:21-25.

ATSDR (Agency for Toxic Substances Disease Registry, (1997). Toxicology Profile for used Mineral-Based Crankcase Oil. Department of Health and Human Services, Public Health Services Press, Atlanta, GA, USA. 8: $83-84$.

Bayer, H., Mitterer, M. and Schinner, F. (1982). Der Einfluss vonlnsektiziden auf mikrobiogene Prozesse in Ah-Materialien 
eines land wirtschaftlich genutzten Bodens. Pedobiologia, 23: 311-319.

Dominguez-Rosado, R. E. and Pichtel, J. (2004). Phytoremediation of soil contaminated with used motor oil. Environmental Engineering Science, 2: 157-168.

Dushoff, I.M., Payne, J., Hershey, F.B. and Donaldson, R.C. (1965).Oxygen uptake tetrazolium reduction during skin cycle of mouse. American Journal of Physiology, 209: 231-235.

Ebulue, M. M., Uwakwe, A. A. and Wegwu, M. O. (2017). Soil lipase and dehydrogenases activities in spent engine oil polluted ecosystem. Journal of Bioinnovation 6 (5), pp: 782-789, IISSN 2277-8330 (Electronic).

Margesin, R. and Schinner, F. (1999). Soil lipase activity a useful indicator of oil biodegradation. Biotechnology Techniques, 13:859-863.

Margesin, R., Schinner, F. and Zimmerbauer, A. (2000). Monitoring of bioremediation by soil biological activities. Chemosphere, 40: 339- 345.

Moffat, N. (1995). Methods in organic manure measurement. AgronomyJournal of Soil Science, 41:101 - 103.

Nelson, D. L. and Cox, M. M. (2008). Lehninger, Principles of biochemistry. [G4] Glossary.

Öhlinger, R. (1996). Dehydrogenase activity with the substrate TTC. In:
Schinner,F.,Öhlinger,R., Kandeler, E. and Margesin, R. (eds.): Methods in Soil Biology. Verlag Berlin Heidelberg, Springer, pp 241-243.

Osubor, C. C. and Anoliefo, G. O. (2003). Inhibitory effect of spent lubrication oil on the growth and respiratory function of Arachis hypogea L. Benin Science Digest, 1:73-79.

Osuji, L. C. and Ezebuiro, P. E. (2006). Hydrocarbon contamination of a typical mangrove floor in Niger Delta. Journal of Environmental Science and Technology, $3(3): 313-320$.

Rosado, E. D.and Pichtel, J. (2003). Chemical characterization of fresh, used and weathered mtor oil via GC/MS, NMR and FTIR techniques. Journal of Natural Resources and Environmental Management, 112 (2) pp: 109 - 116.

Schinner, F., Ohlinger, R., Kandeler, E. and Margesin, R. (1996). Methods in soil biology. Springer, Heidelberg. Pp. 370376.

Tabatabai, M. A. (1982).Soil enzymes, Dehydrogenases. In: Methods of Soil Analysis. Part 2. Chemical and Microbiolgical Properties (Eds. R.H. Miller and D.R. Keeney). Monography, 9, ASA and SSSA, Madison, WI. 